\section{Infant mortality in Cabinda, \\ Angola: challenge to health public policies}

\section{Mortes infantis em Cabinda, Angola: desafio para as políticas públicas de saúde}

\author{
Razão Simão' \\ Paulo Rogério Gallo" \\ 'Department of Public Health of Cabinda, Angola. \\ "Department of Maternal and Child Health, School of Public Health, \\ Universidade de São Paulo - São Paulo (SP), Brazil.
}

\begin{abstract}
Objective: To critically discuss, describe and analyze the data on infant mortality provided by public health services of Cabinda, Angola. Method: The deaths of children aged less than one year old in 2007 and 2008 were analyzed in the Cabinda province. Provincial hospital records and those of the WHO office were used due to the limited quality and availability of official information. Results: In 2007, 11,734 children were born, and 366 of them died in their first year of life: 113 on the first day, 87 by the $28^{\text {th }}$ day and 166 in the remaining 337 days. In 2008, 13,441 children were born and 275 died; 109 died on the first day and 69 by the $28^{\text {th }}$ day. Malaria was the main cause of death (one out of three). Pneumonia was the second cause in 2007 and the third in 2008, presenting consistent reduction, from 65 to 40 deaths. Cases of diarrhea from 2007 (9.83\%) decreased to $3.27 \%$ in 2008. Tetanus accounted for about $5 \%$ of all deaths. Perinatal causes increased in proportion, particularly neonatal asphyxia (17.75\% in 2007 and $26.90 \%$ in 2008) and prematurity (13.38\% in 2007 and $17.45 \%$ in 2008). Conclusions: Improvements in the quality of prenatal care, attendance during delivery and to new born risk, would reduce infant mortality. The lack of sanitation, inadequate water supply and poor access to health services played an important role as determinants of infant mortality observed in Cabinda. This study highlights the need to reorganize the civil registration system.
\end{abstract}

Keywords: Infant mortality. Vital statistics. Health status indicators. Medical records. Information systems. Health services. 


\section{Resumo}

Objetivo: Discutir criticamente, descrever e analisar os dados e óbitos infantis disponibilizados pelos serviços públicos da província de Cabinda, Angola. Método: Foram estudados óbitos de menores de um ano de idade, em 2007 e 2008, da província de Cabinda. Utilizaram-se os registros do hospital provincial e do escritório provincial da Organização Mundial da Saúde (OMS) de Cabinda, considerando as dificuldades e limitantes da qualidade e disponibilidade das informações locais. Resultados: Em 2007, nasceram 11.734 crianças; destas, 366 morreram no primeiro ano de vida: 113 no primeiro dia e 87 até $028^{\circ}$ e 166 nos 337 dias restantes Em 2008, nasceram 13.441 e morreram 275 crianças; destas, 109 crianças no primeiro dia de vida e 69 até o $28^{\circ}$ dia de vida. A malária destaca-se como principal causa de morte (uma a cada três). A pneumonia, segunda causa em 2007 e terceira em 2008, com expressiva redução de 65 para 40 óbitos, respectivamente. As diarreias de 2007 (9,83\%) diminuíram em 2008 (3,27\%). O tétano responde por cerca de $5 \%$ das mortes. As causas perinatais aumentaram de proporção, particularmente a asfixia neonatal $(17,75 \%$ em 2007 e $26,90 \%$ em 2008$)$ e a prematuridade (13,38\% em 2007 e 17,45\% em 2008). Conclusões: Melhorias na qualidade de assistência pré-natal, ao parto e ao recém-nascido de risco poderiam reduzir a mortalidade infantil. A falta de saneamento básico, condições inadequadas de abastecimento de água e acesso aos serviços de saúde revelaram ter papel importante como condicionantes da elevada mortalidade infantil observada em Cabinda. Evidencia-se a necessidade de reorganizar o sistema de registro civil.

Palavras-chave: Mortalidade infantil. Estatísticas vitais. Indicadores básicos de saúde. Registros médicos. Sistemas de informação. Serviços de saúde.

\section{Introduction}

Vital events are inherent processes to the human being. However, being born and dying, growing up and getting sick, as natural as can be, do not occur without an efficient cause to produce them.

Death during childhood is the interruption of life in its early process; therefore, something unexpected happens in the economy of the vital process. Understanding why there is death in childhood is not only a philosophical speculation, but is it especially a way to try and suppress the factors that are causing it, thus allowing the blooming of life, and such right belongs to all of humanity.

The value of life is not dissociated from the specific culture of the people, their possibilities and survival options, that is, their history. Death, which is a unique and definitive event, represents the last manifestation of people and, when analyzed from the collective point of view, it can be interpreted as an indicator or final product of the life conditions of communities; if analyzed like that, it presents major differences both in magnitude and in the list of causes ${ }^{1,2}$.

The level of quality of life in a society is difficult to be completely measured. The difficulty lies on the attribution of values to dietary behavior, lifestyles, working conditions, housing, safety, consumption patterns, political relations between peoples and races. There are singular and distinct values, depending on the moment, place and course of life of each society.

However, since life is a supreme value, emphasized and historically defended by all of the cultures, survival conditions can be assessed and compared by means of specific indicators. Among the indicators, the most traditional one is the Coefficient of Infant Mortality (CIM), which measures or indicates the risk of a live newborn infant dying before reaching the age of one. Since it expresses not only the health status of a society, but also its socioeconomic pattern considering these characteristics, it has been universally used as a synthetic indicator of social development and human rights guarantee. 
Indeed, the capacity of societies to defend their survival, thus preserving their ancestry and the lives of their children, it not only a phylogenic discussion, but it also reveals their level of organization, respect, solidarity and internal coherence; therefore, its level of social development ${ }^{2,3}$.

When considering the death of children, both in absolute numbers and standardized in coefficients, Angola stands out negatively; in 2012 , it was among the first ten countries when compared to the others assessed by the Interagency Group for Child Mortality Estimation (IGME) ${ }^{4}$. However, the agency explains the difficulty to assess the magnitude of the problem.

According to IGME, the inconsistency of the available data is owed to a set of reasons, especially the incorrect notification of the age of death, sampling and selection biases and inconsistency of exploratory research that compromise the validation of the results.

Anyway, IGME estimates that in 2011 there were 96 deaths among children aged less than one year old in one thousand births. In this scenario, between 1990 and 2011, Angola would have presented one of the lowest reduction rates of infant mortality throughout Sub-Saharan Africa (2.1\% a year), establishing the country with the $9^{\text {th }}$ worse infant mortality rate among the 50 countries composing the studies of Sub-Saharan Africa ${ }^{4}$.

\section{Angola: geopolitical aspects}

Angola is placed in the Austral and Central Africa, and has 1,271 villages, 475 communes, 163 cities, 18 provinces and an estimated population of $18,498,000$ inhabitants in 2009, composed of several peoples, ethnicities, and cultures, as well as a diversity of languages, even though Portuguese is the official language ${ }^{5}$.

The independence of Angola (November $11,1975)$ was not the beginning of peace, but the start of a new open war. Three nationalist groups - Popular Movement for the Liberation of Angola (MPLA), National Front of Liberation of Angola (FNLA) and the National Union for the Total Independence of Angola (UNITA - began to fight for the control of the country, especially the capital, Luanda. From the 1970s on, Angola lost its statistical tradition of demographic analysis coming from the colonial time. The civil registration system, which worked reasonably in urban areas in the colonial period, was deteriorated to the point of no longer being used with statistical purposes ${ }^{6}$. Currently, the civil registration system works with many difficulties and, in certain regions, it is inexistent.

Angola lived through 5 centuries of Portuguese colonization (1475 - 1975), 14 years of national struggle for independence (1961 - 1975) and more than 27 years of civil war (1975 - 2002). After a long civil war that only ended on February 22, 2002, with the death of Jonas Malheiro Savimbi, the country is going through a period of peace and reconstruction, but the conflict was marked in history, in culture and in the life and look of the Angolans, who still live in the logic of survival ${ }^{7}$.

\section{Cabinda: geopolitical aspects}

The province of Cabinda stands out socially and geographically from the Angolan territory: it is situated to the north of Angola in the region of Central Africa, with four cities, eight communes and an estimated population of 518,266 inhabitants. It is located $60 \mathrm{~km}$ from the Angolan territory and $480 \mathrm{~km}$ from Luanda, according to information reported directly to the researcher by the Cabinet of Planning Studies and Statistics (GEPE), of the government of Cabinda, in 2010.

Cabinda is rich in natural resources. However, there are several logistical and sociocultural difficulties to establish preventive actions, like, for instance, the lack of fuel to conserve and maintain the cold chain, which is an essential and important structure to implement immunization, as well as social recognition, and indirectly the recognition of the government, in relation to the important of birth registration.

Births in the province should be verbally declared. In business days, birth registration is conducted in maternity wards by the 
employees of the "conservatories" of the civil registry. However, births on Saturdays, Sundays and holidays are not registered, and many parents do not return on business days to register their children. It is very common to find children at school age without registration.

As to death, it is up to the family to declare it in 30 days or even after this period in the "conservatory" or in the civil registry of the region where the casualty took place; that is, where the body is, since the fees are paid referring to the fine for the delay in the declaration ${ }^{6}$.

If the birth and death of the child is declared simultaneously, it should be registered as birth and, afterwards, in the same book, as death.

\section{Infrastructure}

Even though the urban zone disposes of a drinkable water distribution system for almost the entire province, it usually goes through long periods of irregular supply, especially in peripheral areas, due to the lack of fuel and constant damage in the submerse pumps to meet the demand.

Medical and sanitary care is offered in 138 health services (health units, health centers, 3 city hospitals and 1 province hospital which has the only biochemical public clinical analysis laboratory). In 2010, the province of Cabinda had 370 hospital beds (for all of the services), distributed as follows: 225 in the city of Cabinda, 40 in Cacongo, 40 in Buco-Zau and 35 in Belize.

It is worth to mention that the set of the Cabinda province counted on 2,265 health professionals, mostly health agents and sanitary visitors, with basic schooling ${ }^{8}$. The provincial mean is of 0.71 beds per 1 thousand inhabitants, which is far from meeting the demands, considering the hospital admission of more than one patient per bed observed in some services, according to the experience of the author of this study including in pediatrics and gynecology sectors of the province hospital.
In 2010, public health services in the province of Cabinda had 115 doctors. In 2010, this number represented approximately 0.22 doctors for 1 thousand inhabitants of the province ${ }^{8}$.

According to unpublished information from the Health Province Board (DPS) of GEPE, $48 \%$ of the public network had good physical conditions, $25 \%$ was reasonable and $27 \%$ was considered to be bad or closed. The elements considered in this classification were: condition of the physical structure, that is, the state of conservation of walls, coverage, doors and windows, electrical network, sanitary installation, sewage network, painting and equipment functioning. However, it was not possible to gather information about the quality of the equipment and the clinical analysis laboratory, nor about its use (or underuse); however, according to the experience of the researcher, from the structural point of view, the information provided by the province board seems to be consistent.

In many rural health units, the presence of doctors is not the reality of health teams. Problems related to recruitment (lack of doctors in the region/country) contribute with this situation, as well as placement and fixation (lack of policies stimulating the internalization of professionals). To that precarious human resources situation it is possible to add the lack of obstetricians and pediatricians, as well as the choice of doctors and graduated professionals nurses, physical therapists, occupational therapists, dentists, among others - to work in private clinics, with clear preference to work in the capital of the country (Luanda), where there are more attractions, better financial possibilities and an interesting private health system ${ }^{5}$. In daily practice, doctors are often replaced by medium or basic nursing technicians.

Despite the recognized importance to preserve, restore and develop life, the health sector in the province of Cabinda is historically one of the most deprived and disfavored 
ones when compared to others sectors of the public administration of Angola. According to the researcher's opinion, the sector suffers from huge needs and administrative and financial deficiencies, as well as of physical structure and even of human resources (number and quality of the professionals).

\section{Education}

There are public schools in Cabinda, however, they function badly. According to information by GEPE, the set of public and private network accounts for 276 schools: Primary School (231); $\left(\right.$ Pre $-6^{\text {th }}$ grade to Cycle I (26); $7^{\text {th }}, 8^{\text {th }}$ and $9^{\text {th }}$ grade and Cycle II (15); $10^{\text {th }}$ to $12^{\text {th }}$ grade (4). Cycle III has 1 Private University of Angola (UPRA), 1 Lusíada University, 1 University Center of Cabinda (CUC) 11 de Novembro and 1 Medical School.

There are no available data about the schooling rates of the general population or children and adolescents.

Therefore, this paper is an opportunity to discuss with the scientific community and the population considerations about the rates obtained from the infant mortality data made available by the local public services, and it aims at showing inconsistencies that are possible to correct.

It is important to consider the coexistence of the dialogue between public policies of Cabinda, Angola, and the epidemiological data expressed in infant mortality rates. Besides, there is also the need for political will from the governors in order to improve the information in the field of vital statistics.

\section{Method}

\section{Design}

A descriptive study structured from a data base built with the information contained in register books of deaths and births under the responsibility of the Cabinda Provincial Hospital. Births and deaths in the first year of the child, the age of death, the underlying cause, and the time of survival are considered as independent variables, calculated according to the principles of survival analysis ${ }^{9}$. The respective CIMs of 2007 and 208 were calculated for children registered in the books of the hospital (city of Cabinda). Dates of birth and death in the other cities that compose the province of Cabinda (Cacongo, Buco-Zau, Belize) are not available, therefore, not presented in this article.

\section{Ethical considerations}

The study was authorized by the local government (Secretariat of Health of Cabinda and Angola) and is in accordance with the Brazilian rules from resolution n. 196/96, of the Research and Ethics National Committee.

\section{Study area}

Data come from the coverage area of the Regional Hospital of the Cabinda province. Apart from capital hospitals, this is the largest and most organized one in the region. Even though its physical structure was repaired during the period of data collection, it presented the registers of births and deaths of all the months of 2007 and 2008. This hospital receives the childbirths of the province and pregnant women from the other cities that present with high risk pregnancies.

It is worth to mention that hospitals located in the other cities do not keep records or death certificates. Statistics in these hospitals is fulfilled by the Secretariat/Hospital Medical File Service (SAME) of each of them, being forwarded to the head of the Public Health Department of the province (DSP). There is no information about criteria or the systematics to fulfill the forms (therefore, there is no supervision over the results and/or defined operational norms).

\section{Data collection process}

Data collection was conducted from December 2009 to March 2010, with the 
direct participation of the regional office of WHO in Cabinda for immunization and poliomyelitis. Collection was performed with the institutional support of technicians in charge of epidemiological survey and statistics of the respective hospitals. The information from register books of death and birth was transcribed under the responsibility of the province hospital.

It is worth to mention that register books are organized in sequential pages of regular notebooks, on which, at the end of the working day, employees of the maternity ward and pediatrics write information with a pen or a pencil about the children who were born and survived/died during the respective working shift. Therefore, since the information is written down at shift change times, there may be mistakes, once this is usually a moment when employees are in a hurry and experiencing embarrassment related to the entrance-exit work time.

One example, even if only in the Cabinda Provincial Hospital - although it is allowed by the authorities - concerns a reward given to employees of the ward who do not have deaths registered during their shifts, with a bonus to their salaries. In the opinion of some ward technicians, this initiative would lead to the "forgetfulness" in death registration.

Besides these serious questions concerning the registration of vital statistics, the deaths of children in the first 24 hours after labor are systematically ignored in the routine of the hospitals.

With regard to urgency and emergency care, which is in charge of child care, the hospital registration can only be made after the child stays in the emergency sectors for at least 24 hours. The death of children during the first 24 hours of hospital stay is considered to be an extra-hospital death; therefore, the hospital does not take any responsibility concerning the certificate, registration in the conservatory or other social registrations.

Even with all of these limiting factors for the quality of information, the objective was to value the existing ones, by transcribing them with the help of the aforementioned technicians to the personal notes of the researcher, which were afterwards typed into an Excel spreadsheet and analyzed in this study.

It was possible to characterize births, age of death and underlying cause of death of all of the children registered in the books of the province hospital.

Chart 1 presents a summary of these difficulties related to data collection.

In many locations of the rural, suburban and periurban zones of Cabinda, most deliveries take place at home and are made by traditional midwives who have no connection with the health system. In these cases, there is no need to communicate the occurrence of births or deaths of newborns.

In these locations, if there is the need for a C-section, the long waiting hours for transportation and the journey to the province hospital usually result in extra-hospital deaths of mothers and newborns.

The evasion and/or invasion of births and deaths should be considered as possible ${ }^{10}$ due to the constant presence of pregnant women from the two Congos that use the health service of Cabinda; despite its limitations, its quality is still considered to be better than the one offered by the governments of the neighboring countries.

According to the researcher, it is supposed that due to the gratuity of sanitary and medical services in Cabinda, which does not happen in the two Congos, the number of birth and death evasions and invasions should be big. However, despite recognizing the importance of this information to quantify births and deaths, it was not possible to measure it as to magnitude or as to the main direction of the effects of migration forces (evasion or invasion) in the birth and death rates of the children observed in this study.

\section{Results}

In Figure 1, the diagram to compare the mean and the absolute number of infant mortality is observed, according to month of occurrence, in 2007 and 2008, in the Cabinda Provincial Hospital. It is observed that, in 2008, there was expressive 
Chart 1 - Distribution of information collected from various municipalities in the province of Cabinda, according to data availability and months of year.

Quadro 1 - Distribuição das informações coletadas dos diversos municípios da província de Cabinda, segundo disponibilidade dos dados e meses do ano.

\begin{tabular}{|c|c|c|c|c|c|c|c|c|c|c|c|c|c|c|c|c|}
\hline \multirow{4}{*}{ Months } & \multicolumn{16}{|c|}{ Years } \\
\hline & \multicolumn{8}{|c|}{2007} & \multicolumn{8}{|c|}{2008} \\
\hline & \multicolumn{2}{|c|}{ Cabinda } & \multicolumn{2}{|c|}{ Cacongo } & \multicolumn{2}{|c|}{ Buco-Zau } & \multicolumn{2}{|c|}{ Belize } & \multicolumn{2}{|c|}{ Cabinda } & \multicolumn{2}{|c|}{ Cacongo } & \multicolumn{2}{|c|}{ Buco-Zau } & \multicolumn{2}{|c|}{ Belize } \\
\hline & LB & $\mathrm{D}$ & LB & $\mathrm{D}$ & LB & $\mathrm{D}$ & LB & $\mathrm{D}$ & LB & $\mathrm{D}$ & LB & $\mathrm{D}$ & LB & $\mathrm{D}$ & LB & $\mathrm{D}$ \\
\hline Jan. & 918 & 38 & * & * & * & * & * & * & 855 & 23 & * & * & * & * & * & $*$ \\
\hline Feb. & 954 & 39 & * & $*$ & * & * & * & * & 661 & 27 & * & * & * & $*$ & * & * \\
\hline Mar. & 1.126 & 44 & * & * & * & $*$ & * & * & 1.317 & 24 & * & * & * & * & * & * \\
\hline Apr. & 1.153 & 29 & * & $*$ & $*$ & $*$ & * & * & 1.524 & 32 & $*$ & * & * & $*$ & * & * \\
\hline May & 1.311 & 37 & * & * & * & $*$ & * & * & 1.561 & 26 & * & * & * & $*$ & * & * \\
\hline Jun. & 1.112 & 30 & * & * & * & $*$ & * & * & 1.387 & 22 & * & * & * & $*$ & * & * \\
\hline Jul. & 1.055 & 29 & * & * & * & * & * & * & 1.359 & 19 & * & * & * & $*$ & * & * \\
\hline Aug. & 870 & 30 & * & $*$ & * & $*$ & * & * & 1.097 & 17 & * & * & * & $*$ & * & * \\
\hline Sep. & 916 & 19 & * & $*$ & * & $*$ & * & * & 906 & 18 & * & * & * & $*$ & * & $*$ \\
\hline Oct. & 750 & 22 & * & $*$ & * & $*$ & * & * & 945 & 22 & $*$ & * & * & $*$ & * & * \\
\hline Nov. & 788 & 26 & * & $*$ & * & $*$ & * & * & 917 & 24 & * & * & * & $*$ & * & $*$ \\
\hline Dec. & 781 & 23 & * & $*$ & * & $*$ & * & $*$ & 912 & 21 & * & $*$ & * & $*$ & * & $*$ \\
\hline Total & 11.734 & 366 & 320 & 17 & 372 & * & 292 & 24 & 13.441 & 275 & * & 02 & 473 & 41 & 299 & 38 \\
\hline
\end{tabular}

*without information; LB: live birth; D: deaths.

*sem informação; LB: nascidos vivos; D: óbitos.

decrease in the death of children when compared to 2007 (91 less casualties than in 2007). However, when the distribution of deaths according to month of occurrence is observed, there is no concentration in specific months.

Table 1 shows the number and the percentage of deaths in the Cabinda Provincial Hospital in 2007 and 2008, according to underlying cause. The first underlying cause of death among children aged less than one year old was malaria. Alone, this cause responds approximately to one death out of each three children that passed away. On the other hand, there were registers of congenital malformations only in 2007, and yet it responded for a small proportion of two deaths (1.09\%). Among the infection contagious diseases, tetanus responds for about $5 \%$ of the deaths.

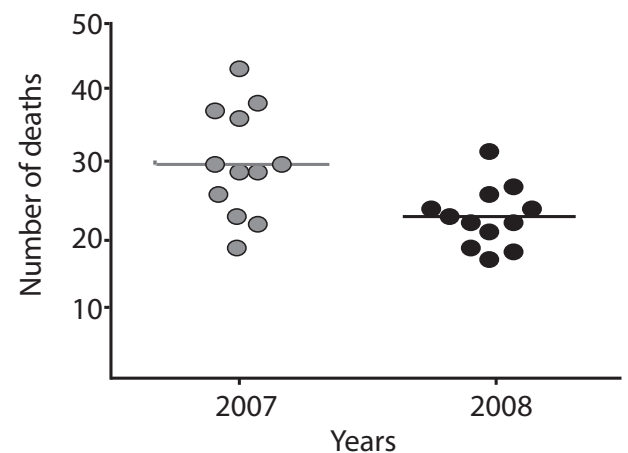

Figure 1 - Diagram to compare the mean and number of infant deaths by month of occurrence, in 2007 and 2008, in the Cabinda Provincial Hospital, Angola.

Figura 1 - Diagrama para comparação das médias do número de óbitos infantis, segundo mês de ocorrência, em 2007 e 2008, no Hospital Provincial de Cabinda, Angola. 
Table 1 - Number and percentage of infant deaths occurred in the Cabinda Provincial Hospital in the years 2007 and 2008, according to underlying causes.

Tabela 1 - Número e porcentagem dos óbitos infantis ocorridos no Hospital Provincial de Cabinda nos anos de 2007 e 2008, segundo causa básica.

\begin{tabular}{|c|c|c|c|c|c|c|}
\hline \multirow{3}{*}{ Cause } & \multicolumn{4}{|c|}{ Years } & \multirow{2}{*}{\multicolumn{2}{|c|}{ Total }} \\
\hline & \multicolumn{2}{|c|}{2007} & \multicolumn{2}{|c|}{2008} & & \\
\hline & $\mathrm{n}$ & $\%$ & $\mathrm{n}$ & $\%$ & $\mathrm{n}$ & $\%$ \\
\hline Malaria & 108 & 29.50 & 78 & 28.36 & 186 & 29.01 \\
\hline Diarrhea & 36 & 9.83 & 09 & 3.27 & 45 & 7.02 \\
\hline Pneumonia & 65 & 17.75 & 40 & 14.54 & 105 & 16.38 \\
\hline Asphyxia & 64 & 17.48 & 74 & 26.90 & 138 & 21.52 \\
\hline Prematury & 49 & 13.38 & 48 & 17.45 & 97 & 15.13 \\
\hline Tetanus & 20 & 5.46 & 12 & 4.36 & 32 & 4.99 \\
\hline Sepsis & 18 & 4.91 & 11 & 4.00 & 29 & 4.52 \\
\hline Meningitis & 02 & 0.54 & 03 & 1.09 & 05 & 0.78 \\
\hline $\begin{array}{l}\text { Congenital } \\
\text { malformation }\end{array}$ & 04 & 1.09 & 00 & 0.00 & 04 & 0.62 \\
\hline Total & 366 & 100.00 & 275 & 100.00 & 641 & 100.00 \\
\hline
\end{tabular}

Diarrheas, which held a high position in 2007 (9.83\%, corresponding to 36 cases), decreased in 2008 ( $3.27 \%$, that is, 9 cases).

Perinatal causes stood out their importance, especially neonatal asphyxia $(17.75 \%$ in 2007 and $26.90 \%$ in 2008) and prematurity (13.38\% in 2007 and $17.45 \%$ in 2008 ), proportions that indicate improved care, sanitary or breastfeeding conditions for children aged less than one year old in 2008. Mortality caused by prematurity enables to verify there were no changes in the specific rates in the two assessed years. The reduction of 65 to 40 deaths due to pneumonia among children is the second or third most important cause of death among children in Cabinda, together with neonatal asphyxia. In this study, there were no records that could place Aids as a cause of death.

The survival analysis of children who died in the Cabinda Provincial Hospital presented in Figure 2 shows us several points for reflection and approach, characterizing the proportion of deaths in children younger than 1 day, 7 days, 28 days and 365 days. The first point that stands out is that in 2008 deaths $(n=275)$ were concentrated in the first month of life (62.54\%).

In 2007, out of the 366 deaths, it is observed that 200 (54.64\%) occurred in children aged less than 28 days old, and on the first day of

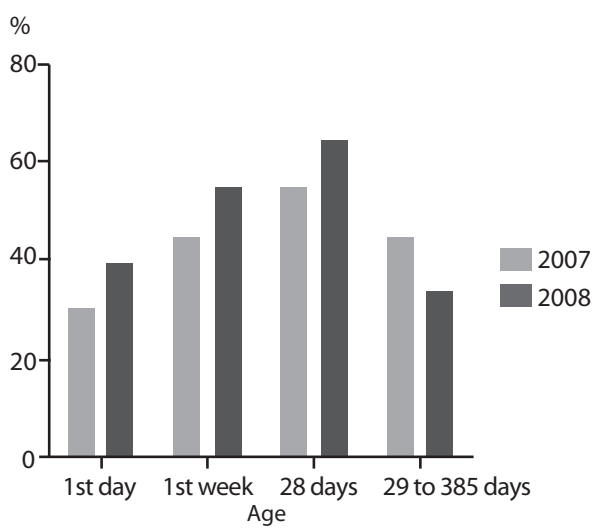

Figure 2 - Distribution of infant deaths occurred in the Cabinda Provincial Hospital in the years 2007 and 2008, according to survival analysis.

Figura 2 - Proporção dos óbitos infantis ocorridos no Hospital Provincial de Cabinda nos anos de 2007 e 2008, segundo análise de sobrevida.

life, 113 newborns passed away (30.90\%). Values show that in 2008 more children died on the first day of life $(n=10)$ than in the 27 following days $(\mathrm{n}=69)$, and more than in the 11 following months $(n=97)$.

It is worth to mention that the CIM calculation is only possible for the data available in the city of Cabinda. In this sense, in 2007 there were 366 deaths for 11,734 live newborns (31.2 for one thousand live newborns), and in 2008, there were 257 deaths for 13,441 live newborns (20.4 for one thousand newborns). Since the number 
of births increased, the reduction of CIM (33\%) is more intense than the absolute reduction of the number of deaths $(24 \%)$.

It is also possible to use these registered numbers of death to estimate the subregistration of deaths and births occurred on weekends and holidays. By considering the data collected in 2008 and 2007, it is possible to admit that in this period there were approximately 257 and 366 deaths (mean of 311.5), a mean of 0.85 deaths a day. Considering there were 54 weekends, it is possible to calculate the number of deaths in 91.8 children, potentially unregistered ones, and such value could be added to the analyzed data without being far from the reality of the region. Besides, the number of official national holidays would add 10 days in which conservatories were closed, thus preventing the registration of infant mortality, given the probability that deaths are not notified because it was not mandatory. Therefore, besides the whole complexity of the mortality registration system, there is still possibly a sub-notification of infant mortality of about $100(91.8+8.5)$ children throughout the year, which take place on weekends and holidays.

With regard to the birth estimates, it does not seem appropriate to consider it in this article, since the birth registration can be made after pecuniary fee, be it on the first days of life or at any point of the child's life.

\section{Discussion}

One of the central questions of this study is the low reliability of the official data of Sub-Saharan Africa as estimators of infant mortality in the region ${ }^{11,12}$. In this sense, it is necessary to analyze the epidemiological estimates of the United Nations ${ }^{4,13}$.

Regardless of the magnitude of the problem, this study registers the reduced number of children aged less than one year old in Cabinda in these two analyzed years. The phenomenon of reduced infant mortality rates is also observed in geographically close regions in the years of 1990 and 2011, as observed by CIM of: Angola (114 in 1990 and 96 in 2011); (Congo (75 - 64); Namibia (49 - 30); and RD Congo (117 - 11) $)^{11}$.

The death of children is an important indicator of health, as well as of social conditions and values ${ }^{1-3}$. To analyze the numbers of the province of Cabinda, it is necessary to contextualize their interpretation inside the population dynamics to which the province is subjected. Therefore, it is first necessary to interpret, considering that the explosive growth of the population in the cities of Cabinda has contributed with the progressed deterioration of life conditions, once this growth has not been followed by the public power or basic health and social care.

The presented dynamics also reflects on the organization of the urban and periurban space, which is mostly deprived from the benefits coming from basic sanitation, such as regular drinkable water supply, waste collection and sewage. Such policy leads to the increased number of breeding sites, the proliferation of mosquitoes and the contamination of the environment, thus causing higher occurrences of malaria and diarrheic diseases among children. According to Laurenti et al. ${ }^{8}$, people's lives and the environmental conditions they live in are called social health determiners, which are the main determiners of infant mortality.

It is important to emphasize that there were many difficulties to access data in this study: few qualified people to find and separate the notes corresponding to the registrations and little interest of the hospitals to keep information accurate and updated concerning deaths and births. Besides, it was difficult to check for data consistency together with the families (verbal autopsy ${ }^{14}$ ), be it for problems of physical access or for the lack of resources or the time between the occurrence of death and its certification. Therefore, throughout this discussion, there are many doubts about the real possibility to understand the dimension of infant mortality in Cabinda. According to the researcher, even in the Cabinda Provincial Hospital, the several births registered without the assistance of a qualified professional, added to 
the still restricted access to prenatal care, are part of the factors that may contribute with the excessive mortality in the first year of life.

The city hospital of Cacongo presented registration of the total birth and death data of 2007, but they were unavailable from January $1^{\text {st }}$ to September 20, 2007. In this period, there was no register of births or deaths in the books. In 2008, there was no record of births, but there was a record of mortality data.

The city hospital of Buco-Zau presented birth registers of 2007, and death and birth records of 2008. There was no register of death in 2007.

The city hospital of Belize presented birth and death registers of 2007 and 2008.

Anyway, the numbers presented by the province hospital seem to reflect the real magnitude of infant mortality in the region, since they are very opposite to the estimates presented and internationally recognized by WHO, the World Bank and UNICEF, which estimate values between 144 per one thousand births (in 1990) and 96 per one thousand births (in 2011) ${ }^{13}$.

Part of the explanations for the much lower CIM rates found in this study is in the precariousness of civil registry (sub-notification of births and deaths in the region), and such situation concerns the managers of health programs in the city of Cabinda, as well as Human Right activists ${ }^{15,16}$.

Therefore, when the number of children's deaths is analyzed, the precariousness of the Registration System becomes known, as well as the values and the prevalent causes, because they become parameters - even if crude ones - of a difficulty reality to accept or interpret ${ }^{17}$.

It is important to consider that all of the public investments are political decisions that reflect the commitment of political and scientific leaderships with the understanding of life conditions. In this sense, investments are authorized to ensure priorities and management strategies, be them in the direct assistance to health or in the organization of subsystems that constitute it. Vital statistics and other epidemiological data are examples of that, particularly when information is consistent. However, the inconsistency of data and the negligence in data compilation are also valid, since they should be equally understood as indicators of the level of commitment/lack of commitment of public managers with the health of the population.

In the case of early death of children buried in clandestine cemeteries, or sometimes in the backyard of their own house - situations that were not accounted for - it is possible to consider the omission of the State, and also provide a singular opportunity to think about public policies that search for the social development of the population.

It is possible to suppose that the increase in social rights addressed to improving the level of development in the province of Cabinda, Angola, should be based on the awareness of needs and challenges to be faced by the population and its governors. In the presented scenario, the importance of conceiving a new platform of human and social rights in Cabinda is observed, in which there is room for alterity, for the recognition and respect to citizenship. Finally, that the lives of these children can be valued and respected as an non-negotiablevalue in this new and desirable platform.

Even if rare, studies about infant mortality in Angola insistently reinforce malaria as an important cause of death. For Pinto and Alves ${ }^{18}$, in a cross-sectional study conducted in a hospital in Luanda, malaria is responsible for $22.4 \%$ of casualties among children. According to the digital panel of UNICEF ${ }^{18}$, malaria makes one direct victim every $30 \mathrm{sec}$ onds in the world. From this statistics, $90 \%$ of the deaths would be in Africa ${ }^{18,19}$.

As the main cause of death, malaria affects the children of Cabinda ${ }^{12}$, where the control of the disease could directly reduce CIM in $29.0 \%$ (direct deaths caused by malaria), without considering the deaths resulting from the infections acquired by the mothers during pregnancy and that contribute to increase the rates of prematurity and low weight among newborns, as well as the risk of maternal mortality 
and the consequences of orphanage for surviving newborns.

With regard to deaths caused by tetanus in the first year of life, it is important to mention that the vaccination for pregnant women was included in the expanded program of immunizations of WHO after 1974. In 1989, WHO adopted the resolution of eliminating neonatal and maternal tetanus until 1995 by vaccinating pregnant women and clean delivery ${ }^{20}$. Based on this international proposal, it is recommended to introduce vaccination with three doses of tetanic anatoxine and reinforcement among pregnant women in Cabinda.

It is important to assess the information concerning the registered rates of congenital malformation: in the two analyzed years, they are low. It is possible that there was sub-notification of deaths caused by malformation, lack of diagnosis or difficulties to characterize it by technical teams.

For Lansky, França and Leal ${ }^{21}$, the characterization of the incidence of congenital malformation would be related to specific registration problems, difficulties in prenatal tracking, care and diagnosis of malformation in the peri-natal and immediate post-natal period. These facts are indirectly modulated by the socioeconomic conditions of the pregnant women, and point out to the need for investments in the field of prenatal care.

In the cases investigated in this study, most of the children died in the first 28 days of life, with emphasis on the first 24 hours, thus indicating the need to implant and implement health actions in Cabinda that are addressed to reducing neonatal mortality. This situation imposes policies to promote and protect prenatal care, with proper pregnancy follow-up, including improved delivery and newborn care $^{11-21}$.

\section{Conclusion}

Finally, gaps, inconsistencies and deficiencies were observed, both in quality and in quantity, pointing out to the needs for investment and political will to correct them. In places with similar epidemiological profiles, there is evidence of the great percentage of birth and death sub-notification in the analyzed years, and such a fact reinforces the magnitude and the drama associated with the poor quality of health care ${ }^{12,17,22}$.

In this sense, it is important to consider that, even though it is attractive to prioritize investments of resources in curative actions, as well as those of high technology and aggregated value, this study reinforces the perspective of revisiting local health policies and prioritizing preventive activities in the cities of Cabinda. The results also indicate the probable reduction tendency of CIM in Cabinda. Facing the exposed, the implantation of a primary mother-child care network and the permanent investment on the improvement of health information is suggested ${ }^{20,21}$.

Finally, it is worth to mention the need to review the rewarding policies for the reduction of children's deaths in the hospital environment, once it contributes to the non-notification of casualties.

\section{References}

1. Wagstaff A, Bustreo F, Bryce J, Clawson M, WHO-World Bank Child Health and Poverty Working Group. Child health: reaching the poor. Am J Public Health 2004; 94(5): 726-36.

2. Wise PH. Confronting racial disparities in infant mortality: reconciling science and politics. Am J Prev Med 1993; 9(6): 7-16.

3. Telarolli JR. Mortalidade infantil: uma questão de saúde pública. São Paulo: Moderna; 1997.
4. UN Inter-agency Group for Child Mortality Estimation (UNICEF, WHO, WB, UN). Report 2012. Disponível em http://www.childmortality.org/files_v9/download/ Levels\%20and\%20Trends\%20in\%20Child\%20 Mortality\%20Report\%202012.pdf . (Acessado em 16 de outubro de 2012).

5. Giugliani C. Angola, ares de transformação. Rev Bras Med Fam e Com 2008; 3(10): 125-31. 
6. Angola C. Registro civil de nascimentos e de óbitos de Angola. Consulado de Angola. Disponível em http://www. Org/index.php? option=com_content@task. (Acessado em 26 de janeiro de 2012).

7. Kiala PK. Diagnóstico sócio-demográfico de Angola numa perspectiva de integração entre população e desenvolvimento [dissertação de mestrado]. Bélgica: Instituto de DemografiaUniversidade de Louvain-la-Neuve; 1997.

8. Simão R. Relatório técnico Annual, 2007. Departamento de Saúde Pública de Cabinda-Angola. Ministério da Saúde; 2008 (Mimeo).

9. Laurenti R, Mello Jorge MHP, Lebrão ML, Gotlieb SLD. Estatísticas de saúde. $2^{\mathrm{a}}$ ed. São Paulo: EPU; 2005.

10. Avogo WA, Agadjanian V. Forced migration and child health and mortality in Angola. Soc Sci Med 2010; 70(1): 53-60.

11. Kazembe L, Clarke A, Kandala N-B. Childhood mortality in sub-Saharan Africa: cross-sectional insight into small-scale geographical inequalities from Census data. BMJ Open 2012; 2(5): e00144.

12. Liu L, Johnson HL, Cousens S, Perin J, Scott S, Lawn JE, et al. Global, regional, and national causes of child mortality: an updated systematic analysis for 2010 with time trends since 2000 . Lancet 2012; 379(9832): 2151-61.

13. Fundo das Nações Unidas para a Infância (UNICEF). Situação Mundial da Infância. Estatísticas. Disponível em http://www.unicef.org/infobycountry/angola_statistics. html. (Acessado em 26 de janeiro de 2012).

14. Campos D, França E, Loschi RH, Souza MFM. Uso da autópsia verbal na investigação de óbitos por causa mal definida em Minas Gerais, Brasil. Cad Saúde Pública 2010; 26(6): 1221-33.
15. Frias PG, Lira PIC, Vidal SA, Vanderlei LC. Vigilância de óbitos infantis como indicador da efetividade do sistema de saúde: estudo em um município do interior do Nordeste brasileiro. J Pediatr 2002; 78(6): 509-16.

16. Dodds JM, Ellis M. Birth registration is a priority for child survival. J Trop Pediatr 2010; 56(2): 73-4.

17. Victora CG.Measuring progress towards equitable child survival: where are the epidemiologists? Epidemiology 2007; 18(6): 669-72.

18. e Pinto EA, Alves JG. The causes of death of hospitalized children in Angola. Trop Doct 2008; 38(1): 66-7.

19. Fundo das nações Unidas para a Infância (UNICEF).Situação mundial da saúde da infância em 2011. Disponível em http:// www.unicef.org/health/index_malaria.html. (Acessado em 26 de janeiro de 2012).

20. Murahovschi J. Proteção do recém-nascido contra o tétano pela imunização ativa da gestante com antitoxina tetânica. Rev Paul Pediatr 2008; 26(4): 315-20.

21. Lansky S, França E, Leal MC. Mortes perinatais evitáveis em Belo Horizonte-Minas Gerais-Brasil, 1999. Cad Saúde Pública 2002; 18(5): 1389-400.

22. Monteiro CA, Benício MHD’Aquino, Baldijão MFA. Mortalidade no primeiro ano de vida e a distribuição de renda e de recursos públicos de saúde, São Paulo (Brasil). Rev Saúde Pública 1980; 14(4): 515-39.

Received on: 07/12/12

Final version presented on: 04/26/13

Accepted on: 06/05/13 